are unlikely to have come from the top of an accretionary pile because the clasts include acid igneous rock fragments (probably first cycle) and foliated greywacke.
J. HALL
D. W POWELL
M. R. WARNER* $\dagger$
Z. H. M. EL-ISA
O. ADESANYA
B. J. BLUCK

Department of Geology,

University of Glasgow,

Glasgow G12 8QQ, UK

*Department of Geophysics,

University of Edinburgh,

Mayfield Road,

Edinburgh EH9 3JZ, UK

† Present address: Bullard Laboratories, University of Cam-

bridge, Madingley Road, Cambridge CB3 OEZ, UK.

1. Bamford, D. et al. Geophys. J. R. astr. Soc. 54, 43-60 (1978).

2. Davey, F. J. \& Broadbent, M. N.Z. J. Geol. Geophys. 23, 395-406 (1980).

3. Birch, F. J. geophys. Res. 66, 2199-2224 (1961).

4. Christensen, N. I. J. geophys. Res. 70, 6147-6164 (1965).

5. Anderson, O. \& Liebermann, R. C. in Physical Acoustics Vol. 4B (ed. Mason, W. P.) 329-472 (Academic, New York, 1968).

6. Turner, F. J. Metamorphic Petrology-Mineralogical and Field Aspects (McGraw-Hill, New York, 1981).

7. Leggett, J. K., McKerrow, W. S. \& Eales, M. H. J. geol. Soc. Lond. 136, 755-770 (1979).

8. Oliver, G. J. H. \& Leggett, J. K. Trans. R. Soc. Edinb. 71, 235-246 (1980).

9. Brewer, J. A et al Nature 305, 206-210 (1983)

10. Leggett, J. K. (ed.) Geol. Soc. Spec. Publ. 10, (1982).

11. Upton, B. J. G., Aspen, P. \& Chapman, N. A. J. geol. Soc. Lond. 140, 105-121 (1983).

12. Walton, E. K. in Geology of Scotland (ed. Craig, G.) 201-227 (Oliver \& Boyd, Edinburgh, 1965).

13. Bluck, B. J. Trans. R. Soc. Edinb. Earth Sci. 74, 119-136 (1983)

\section{Geomagnetic reversals}

RECENTLY Valet et $a l^{1}{ }^{1}$ presented palaeomagnetic data associated with a pair of reverse-to-normal ( $\mathrm{R}-\mathrm{N})$ polarity transitions from western Crete. The two transition records, differing in age by about $1.2 \mathrm{Myr}$, were found to possess very similar directional field behaviour in that the corresponding paths of the virtual geomagnetic pole (VGP) were shown to be nearly identical. The authors then noted that an earlier reported N-R VGP path from Crete ${ }^{2}$, associated with the transition which closely follows in time the younger of the two $\mathrm{R}-\mathrm{N}$ reversals, is largely discrepant to the other paths. Given these comparisons, the authors conclude, first, that requirements of the standing field model for transition fields ${ }^{3}$ are not satisfied by these data, and second, that the reversal mechanism in the core may be associated with a definite field configuration over some period of time such that successive reversals of the same sense recorded at the same site will be associated with identical VGP paths.

My purpose here is to explore the above argument further. For the authors' assertion to be strictly valid reversals of opposite sense which occur during a time of assumed invariant transitional field

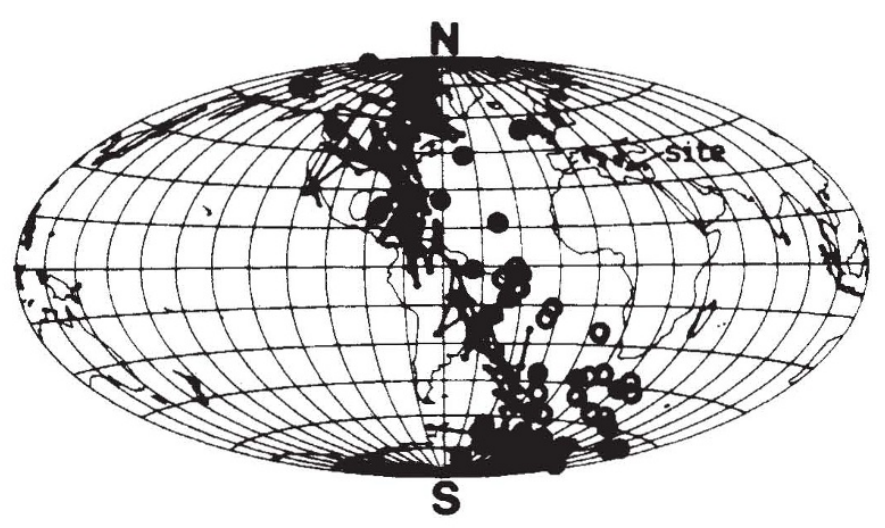

Fig. 1 Paths of the virtual geomagnetic pole associated with three polarity transitions recorded on Crete ${ }^{1,2}$. The drawn path depicts north poles associated with KS06 R-N transition. The solid circles are north poles associated with the older KS02 R-N transition. The open circles are south poles associated with the younger $\mathrm{N}-\mathrm{R}$ transition (after refs 1,2 ).

characteristics should be observed to possess antipodal VGP paths when recorded at the same site. If, on the other hand, the reversal process is asymmetric such that each transition sense is associated with a different field configuration, then antipodal behaviour probably will not be observed. The question now is: how does the VGP path associated with the N-R transition record ${ }^{2}$ compare with the two $\mathrm{R}-\mathrm{N}$ transition paths ${ }^{1}$ ?

Figure 1 shows the highly detailed VGP path associated with the younger (KSO6) $\mathrm{R}-\mathrm{N}$ transition $^{1}$ along with individual VGPs associated with the older (KSO2) $\mathrm{R}-\mathrm{N}$ transition ${ }^{1}$. Also plotted are the individual south VGPs corresponding to the N-R transition ${ }^{2}$. As can be seen in the figure, all three records contain intermediate VGPs which reside along a relatively narrow path west of the site. Indeed, the longitudinal span of this combined path narrows to less than $45^{\circ}$ for nearequatorial poles. Furthermore, an east-towest migration of intermediate VGPs is a common feature of all three paths, where data exist.

For the R-N north pole transition paths to be found in close proximity to the $\mathrm{N}-\mathrm{R}$ south pole transition path implies that the north VGP paths of the former transitions are roughly antipodal to the north VGP path of the latter transition. This finding suggests that the harmonic content during all three reversals was quite similar apart from a complete change in sign of the transition field associated with the N-R event. Such a situation is consistent with a reversal process whose time-dependent configurational characteristics are independent of transition sense.

In this regard, the generalized flooding model $^{4}$ can successfully accommodate these data through a simulated reversal process which begins and extends from the same localized region in the core for all three polarity transitions from Crete. It is interesting, however, that a pair of recently reported sequential reversals ( $R-$ $\mathrm{N}$ and $\mathrm{N}-\mathrm{R}$ ) from Kauai, Hawaii ${ }^{5}$, have nearly identical north pole transition paths. Such a case cannot be strictly explained by the above arguments, but suggests that major changes in the characteristics of the reversal process in the core can occur abruptly between successive geomagnetic transitions.

\section{Physics Department,}

KENNETH A. HOFFMAN

California Polytechnic State University, San Luis Obispo,

California 93407 USA

1. Valet, J.-P., Laj, C. \& Langereis, C. G. Nature 304, 330332 (1983).

2. Valet, J.-P. \& Laj, C. Earth planet. Sci. Lett. 54, 52-63 (1981).

3. Hillhouse, J. \& Cox, A. Earth planet. Sci. Lett. 29, 51-64 (1976).

4. Hoffman, K. A. Earth planet. Sci. Lett. 44, 7-17 (1979).

5. Bogue, S. W. \& Coe, R. S. Nature 295, 399-401 (1982).

VALET AND LAJ REPLY-We have limited our comparison to two reverse-tonormal (R-N) paths from transitions recorded in the same section. Hoffman remarks that a more complete picture can be obtained using antipodal virtual geomagnetic pole (VGP) paths of N-R transitions. Using the south VGPs relative to a N-R transition recorded in a nearby section at Potamida (which we now call KP02), he concludes that the paths of all three transitions are very similar.

The data for this $\mathrm{N}-\mathrm{R}$ transition, however, although detailed, are not rigorously classifiable as category ' $\mathrm{A}$ ' because of lack of points in the second half of the transition ${ }^{1}$, as remarked by Hoffman himself ${ }^{2}$. A new detailed sampling with very precise stratigraphic control yields a much more detailed and still unpublished VGP path quite similar to the previous published one, although some differences exist in the equatorial VGPs. A comparison between the KS06 transition VGPs and the south VGPs of this new record is shown in Fig. 2. We believe that this figure shows that the $\mathrm{R}-\mathrm{N}$ paths from Skouloudhiana and the South Pole $\mathrm{N}-\mathrm{R}$ path from Potamida are not identical (the difference between the two is smaller 